\title{
The Isolation \& Characterization of Several Strains of Naphthalene Degrading Bacteria obtained from oil-contaminated sites
}

\author{
${ }^{1}$ Sidhu.Navdeep, ${ }^{*}$ Rai.Yuvneet, ${ }^{1}$ Kaur.Maninder, ${ }^{1}$ Gupta.Ashna \\ *11CT.Institute of Pharmaceutical Sciences, Dept. Of Biotechnology, Punjab Technical University, Punjab. \\ India \\ Corresponding Author- Yuvneet Rai
}

\begin{abstract}
Naphthalene is the simplest example of a PAH. PAHs occur in oil, coal, and tar deposits, and are produced as byproducts of fuel burning (whether fossil fuel or biomass). Common naphthalene degrading bacteria include Pseudomonas spp., Vibrio spp., Mycobacterium spp., Staphylococcus spp., and Sphingomonas spp. A well studied example of naphthalene catabolism is the naphthalene degradation (nah) pathway of Pseudomonas putida NCIB 98164. Five different isolates have been isolated which are Gram +ve bacteria and they all are naphthalene degrading by nature. It has been concluded that the bacterial strain capable of utilizing naphthalene is able to degrade it in 6 days. From HPLC analysis it is concluded that the concentration of naphthalene decreases as compared from blank solution which do not contain bacteria. HPLC analysis reveals that bacteria catabolises naphthalene within 6 days and decreases its absorbance due to less number of naphthalene present in the solution. Screening for relatively fast-growing naphthalene-degrading bacteria from different sites which were contaminated with crude oil resulted in the recovery of three isolates $B$. naphthovorans strain MN-003, Staphylococcus sp. strain MN-005 and Micrococcus sp. strain MN-006. Although the isolation methods were unbiased and could select for both Gram-positive and Gram-negative bacteria, all three candidate strains were Gram-positive. This dominance of Gram-positive bacteria is demonstrated in the high relative abundances of B.naphthovorans strain MN-003, Staphylococcus sp. strain $M N-005$ and Micrococcus sp. strain MN-006 in the enrichment culture.
\end{abstract}

Keywords: biomass, inoculum, gram staining, p-phenylenediamine, incubation, Bacillus; biodegradation, Gram-positive bacteria, Micrococcus, naphthalene

\section{Introduction}

Polycyclic aromatic hydrocarbons (PAHs) are widely distributed contaminants in diverse environments because of their common association with many anthropogenic activities, such as petroleum refining and incomplete combustion of fossil fuels (Berardesco et al. 1998). PAH bioremediation is considered an effective and environmentally benign cleanup technology as it involves the partial or complete bioconversion of these pollutants to microbial biomass, carbon dioxide and water (Head and Swannell 1999). A successful bioremediation strategy will require an in-depth understanding the factors that influence the biodegradation process and the ecology of pollutant-degrading bacteria (Langworthy et al. 1998). Naphthalene, the simplest PAH, has long been used as a model compound in PAH bioremediation studies. Common naphthalenedegrading bacteria include Pseudomonas spp., Vibrio spp., Mycobacterium spp., Staphylococcus spp., and Sphingomonas spp. (Hedlund et al. 1999). Although many naphthalene-degrading bacteria have been isolated, these bacteria may thrive in one environment but may not be able to compete with other micro-organisms in another environment as environmental conditions will impose a selection pressure on specific types of bacteria. (Laflomme and Hite, 1978 and Jonsen et al., 2005). Furthermore, indigenous bacteria have been shown to out complete artificially introduced strains in several bioremediation investigations (Iwabuchi et al. 1997). Therefore, implementation of a successful bioremediation strategy should necessitate a detailed evaluation of the roles of the indigenous bacteria (Piehler et al. 1999). This study describes the isolation and characterization of several strains of naphthalene-degrading bacteria obtained from oil-contaminated sites. Their ability to compete for naphthalene in mixed culture was also examined. Some of PAHs are degradable by microorganisms and the important biochemical aspects of the PAH-degradation have been relieved. PAHs are nevertheless considered persistent pollutants in soil. Biodegradation using microorganism is usually the preferred not a major route of PAH removal from contaminated environments because of some inherent advantages such as its cost effectiveness and more complete cleanup (Pothuluri and Cerniglia, 1994). Moreover, the physical processes are often limited to aquatic environments only. Although some physical processes such as volatilization, leaching, chemical and photo oxidation are often effective in reducing the environmental level of PA Hs (Bossert and Bartha , 1984 and Heitkamp et al.,1988 ).The microorganisms should possess all the necessary enzymes needed 
to degrade PAHs. It is known that selection or adaptation of PAHs degrading microorganisms as with other chemicals occur as a result of their previous exposure to this substances in the environment ( Lewis et al., 1984 and Spain et al., 1980).However, these adaptations occur slowly, and usually depend on the recalcitrance or biodegradability of the particular substance involved (Spain et al., 1980). This is especially so considering that PAHs usually have low aqueous solubility and thus, are poorly available (low bioavailability) for microbial utilization. (Jonsen et al., 2005).

\section{Material and Method}

Sampling

The soil samples were conducted from 0 to $10 \mathrm{~cm}$ depth of two different sites Guru Gobind Singh refinery, Bhatinda, Punjab. India, Panipat oil refinery, Haryana. India, which were contaminated with crude oil. Samples were collected in sterilized plastic dishes put into flasks containing ice, and carry to the laboratory in less than 24 hours. The experiment was initiated with the soil in the laboratory.

\section{Cultural characteristics}

Colony morphology: It is important to describe the color or pigment of the colony. It also includes descriptive terms for any other relevant optical characteristics such as: opaque, cloudy, translucent, and iridescent. Bacterial colonies are frequently shiny and smooth in appearance.

Cell shape: The form refers to the shape of the colony. These forms represent the most common colony shapes you are likely to encounter. These are circular, irregular, filamentous, rhizoid.

Cell size: The size of the colony can be a useful characteristic for identification. The diameter of a representative colony may be measured.

Catalase reaction: The reaction of catalase in the decomposition of hydrogen peroxide is:

$$
2 \mathrm{H}_{2} \mathrm{O}_{2} \rightarrow 2 \mathrm{H}_{2} \mathrm{O}+\mathrm{O}_{2}
$$

The presence of catalase in a microbial or tissue sample can be tested by adding a volume of hydrogen peroxide and observing the reaction. The formation of bubbles, oxygen, indicates a positive result.

\section{HPLC Analysis}

HPLC was used to evaluate the naphthalene degradation by bacteria. Naphthalene degradation experiments were conducted in the Erlenmeyer flasks containing $100 \mathrm{ml}$ basal mineral medium and naphthalene in a final concentration $0.4 \mathrm{~g} / \mathrm{L}$ was added to the medium. Bacterial strains in $5 \mathrm{ml}$ of nutrient broth were incubated in $30^{\circ} \mathrm{C}$ for $24 \mathrm{~h}, 1 \mathrm{ml}$ of bacterial suspension was added to the medium and placed in the incubator at $30^{\circ} \mathrm{C}$ for one week, cell mass was obtain after centrifuged the sample $6000 \mathrm{rpm}$ for $15 \mathrm{mins}, 2 \mathrm{ml}$ of hexane was added to $5 \mathrm{~mL}$ of mineral medium and was shaken for several times in the glass tubes. Finally $1 \mathrm{ml}$ of upper phase (hexane) was shifted to the sterile tubes and was used for (HPLC) analyses. The (HPLC) system used in this study was a Waters $600 \mathrm{E}$ (USA) model equipped with a degasifier in-line system with helium gas, a sixpart injection valve Rheodyne model with $10 \mathrm{ml}$ loop, a multi-wavelength fluorescence detector (2475, Waters, USA), and an analytical column Novapak C18 from Waters company ( $60 \AA, 150 \times 3.9 \mathrm{~mm}$ I.D, $4 \mu \mathrm{m})$ with a guard column Novapak C18 from Waters Co. (60 Å, 20 x $3.9 \mathrm{~mm}, \mathrm{I} . \mathrm{D})$. In order to control the system and collect data, the software and interface used from Millennium Workstation (Waters) and Waters SAT/IN Module were used, respectively. Cartridge: 8 x $100 \mathrm{~mm}$ Bondapak C18 (a reversed phase column). Solvent: $0.5 \%$ phosphoric acid in $40 \%$ aqueous methanol. The greatest enemy of HPLC is fine particulate matter, which can damage the pumping system and irreversibly block the column. Therefore, all solvents have been filtered through fine membranes (0.4-0.5 micron) and all solutions to be injected must be prepared either with filtered solvent, or filtered as specified later in these notes.

\section{Result \& Discussion}

Isolated bacterial cultures: Different types of colonies were obtained. These organisms are able to degrade naphthalene. (Image.1, 2, 3, 4)

Bacterial slants: These bacterial slants were obtained after incubation at $30^{\circ} \mathrm{C}$.

ISOLATE 1

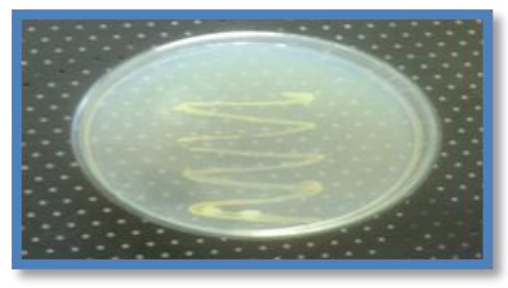

ISOLATE 2

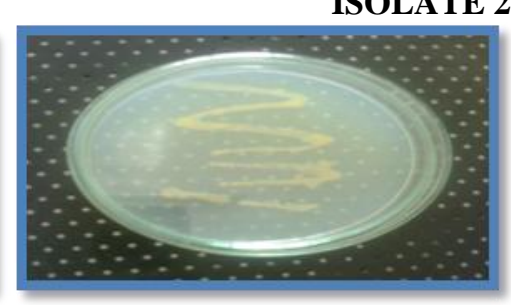


Image.1

ISOLATE 3

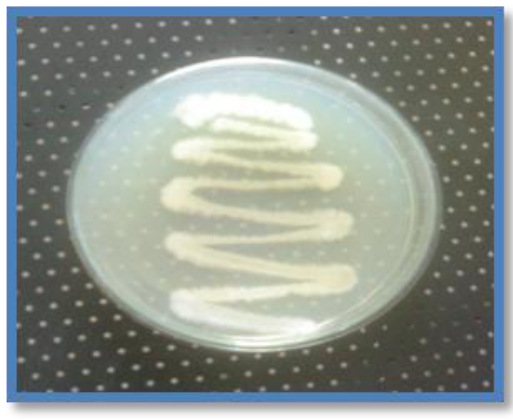

Image.3
Image.2

ISOLATE 4

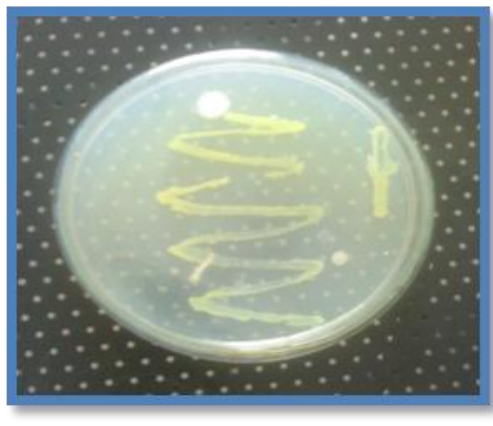

Image.4

Morphological Identification of naphthalene-degrading bacteria

\begin{tabular}{|l|l|}
\hline TEST \\
\hline GRAM \\
STAINING \\
\hline SHAPE \\
\hline COLOUR \\
\hline SIZE \\
\hline CATALASE \\
\hline OXIDASE \\
\hline
\end{tabular}

\begin{tabular}{|}
\hline ISOLATE 1 \\
\hline+ VE \\
ROD \\
(BACILLUS) \\
\hline YELLOW \\
\hline MEDIUM \\
-VE \\
-VE
\end{tabular}

\begin{tabular}{|c|}
\hline ISOLATE 2 \\
\hline+ VE \\
ROD \\
(BACILLUS) \\
\hline ORANGE \\
\hline SMALL \\
- VE \\
-VE
\end{tabular}

$\frac{\text { ISOLATE } 3}{+V E}$

ROUND

(COCCUS)

WHITE

\begin{tabular}{|c|}
\hline ISOLATE 4 \\
\hline+ VE \\
ROUND \\
(COCCUS) \\
\hline DARK YELLOW \\
\hline MEDIUM \\
-VE \\
-VE
\end{tabular}

MEDIUM
+ VE
$-V E$

$-\mathrm{VE}$

$-\mathrm{VE}$

\begin{tabular}{|c|}
\hline ISOLATE 5 \\
\hline+ VE \\
ROD \\
(BACILLUS) \\
\hline TRANSPARENT \\
GREEN \\
SMALL \\
\hline- VE \\
-VE \\
\hline
\end{tabular}

\section{$\underline{\text { Table.1 }}$}

Growth assessment of isolated bacteria in different concentrations of naphthalene The bacterial culture is checked for its growth in naphthalene containing media by spectrophotometer at $600 \mathrm{~nm}$. Following results were obtained after taking absorbance.

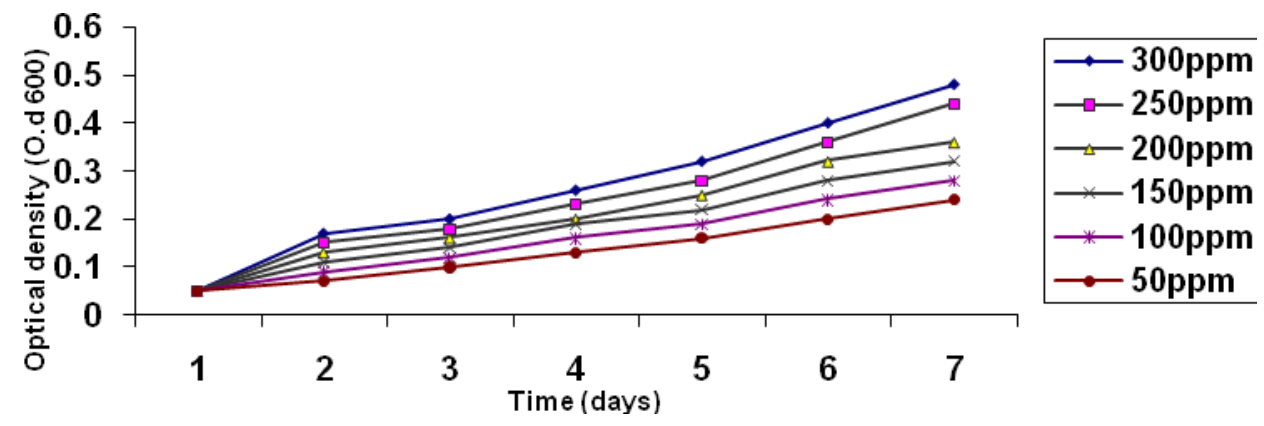

$\overline{\text { Figure.1 The growth curve for bacterial strain in naphthalene containing media was obtained. }}$

\begin{tabular}{|l|l|}
\hline Concentration of naphthalene & O.D. at $600 \mathrm{~nm}$ \\
\hline $50 \mathrm{ppm}$ & 0.1 \\
\hline $100 \mathrm{ppm}$ & 0.2 \\
\hline $150 \mathrm{ppm}$ & 0.3 \\
\hline $200 \mathrm{ppm}$ & 0.4 \\
\hline $250 \mathrm{ppm}$ & 0.5 \\
\hline $300 \mathrm{ppm}$ & 0.6 \\
\hline
\end{tabular}

$\underline{\text { Table.2 }}$

HPLC Results: HPLC of isolate 1 was performed. (figure.2) The following results were obtained which shows that bacteria are capable of degrading naphthalene after 6 days of incubation 


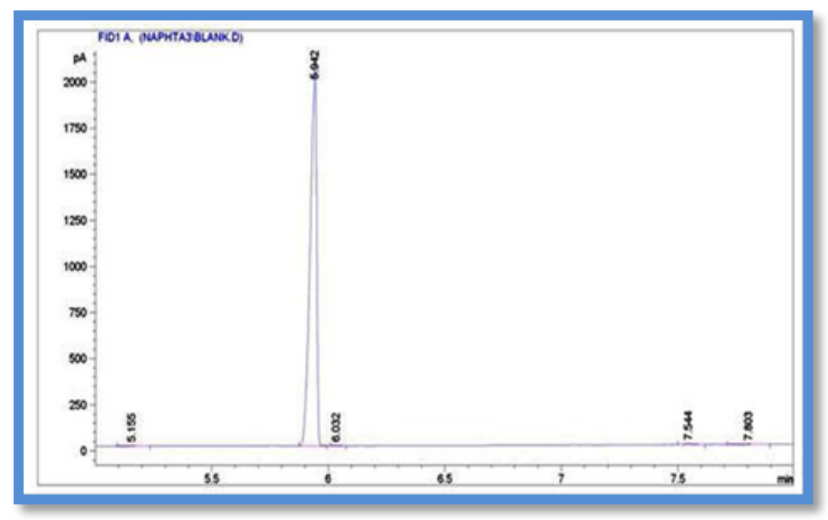

Figure.2

Analysis of Naphthalene $(0.04 \mathrm{~g} / \mathrm{L})$ with HPLC after six days incubation, as blank

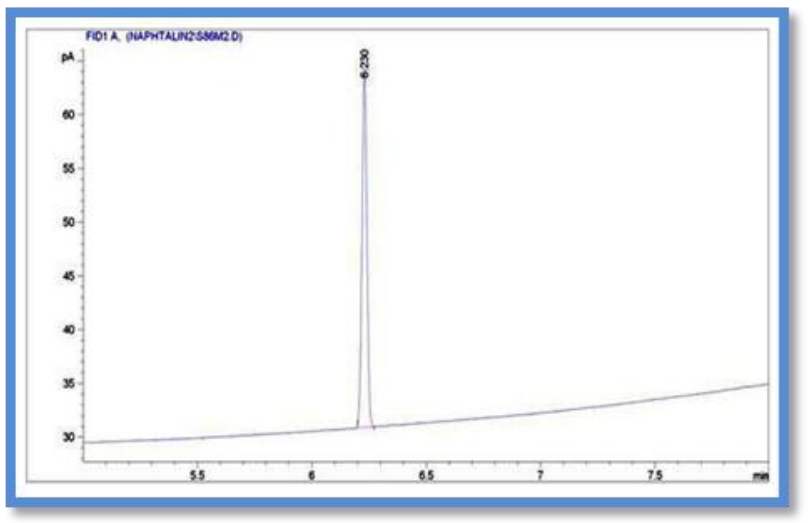

Figure.3

Analysis of Naphthalene $(0.04 \mathrm{~g} / \mathrm{L})$ with HPLC by bacterial isolate 1 , after six days

From the above results it is clear that different types of naphthalene degrading bacteria are present in the oil contaminated soil. All the bacteria were gram positive and are either rod or coccus. In spectrophotometric analysis,(figure1) the growth of bacteria decreases with the increase in the concentration of naphthalene. HPLC analysis reveals that bacteria catabolizes naphthalene within 6 days and decreases its absorbance due to less number of naphthalene present in the solution. But it increases the retention time of naphthalene in the matrix due to the formation of small molecules after degradation of naphthalene.

A total of five naphthalene-degrading bacterial strains were isolated from different sites which were contaminated with crude oil. Three of them were designated as strains MN-003, MN-005 and MN-006 and chosen for further study, because they exhibited relatively fast growth rates on ONR 7a agar plates fed with naphthalene as sole carbon source. Strains MN-003, MN-005 and MN-006 formed visible colonies on ONR 7a agar plate within 7 days, while the slower-growing isolates required at least 10 days. Strain MN-003 was successfully isolated using the direct isolation method, the enrichment isolation method. Strains MN-005 and MN-006 could not be isolated by direct isolation, but were obtained with enrichment isolation. The enrichment culture incubated with naphthalene as sole carbon source exhibited a gradual and significant increase in counts of heterotrophic bacteria, from $4.4 \pm 1.8 \times 10^{5}$ cells ml $^{-1}$ initially to $1.4 \pm 0.4 \times 10^{8}$ cells ml ${ }^{-1}$ after 21 days of incubation. Three colony types were directly associated with strains MN-003, MN-005 and MN-006. Colonies of strain $\mathrm{MN}-003$ could be observed from the beginning of the enrichment experiment, but colonies of strains MN-005 and MN-006 were only detected after a sufficient period of incubation. The relative abundances of these three strains were calculated based on the appearance of the colonies on the ONR 7a agar plates Strains MN-003, MN-005 and MN-006 were present in the enrichment culture incubated for 21 days at concentrations of $5.5 \times 10^{7}, 0.44 \times 10^{7}$ and $2.9 \times 10^{7} \mathrm{cells} \mathrm{ml}^{-1}$, respectively. These cell densities are equivalent to relative abundances of $39.5,3 \cdot 2$ and $20.6 \%$ of total culturable heterotrophic bacteria, and $43.4,3.5$ and $22.7 \%$ of total culturable naphthalene degrading bacteria, respectively. 


\section{Characterization of naphthalene-degrading bacteria}

Characterization of $B$. naphthovorans strain $\mathrm{MN}-003$ has been previously described (Zhuang et al. 2002). Strain MN-005 is spherical in shape, Gram-positive, catalase-positive and oxidasenegative. Cells ranged between 0.6 and $1.3 \mu \mathrm{m}$ in diameter when grown in broth 216 media at $25^{\circ} \mathrm{C}$. Strain MN005 grew at salinities ranging from $0 \cdot 28$ to $5 \%$ and temperatures ranging from 15 to $37^{\circ} \mathrm{C}$. Strain $\mathrm{MN}-006$ is spherical in shape, Gram-positive, catalase-positive and oxidase-positive and occurs in pairs, in triplets and as tetrads. Cells ranged between 0.4 and $1 \mu \mathrm{m}$ in diameter when grown in marine broth 2216 media at $25^{\circ} \mathrm{C}$. Strain MN-006 grew at salinities ranging from 0.28 to $7 \%$ and temperatures ranging from 15 to $41^{\circ} \mathrm{C}$. API ZYM and API 20E results of the three isolates are summarized in . Strain MN-003 can use naphthalene, benzene, toluene, xylene and diesel oil as sole carbon source. Strain MN-005 can only use naphthalene as sole carbon source. Strain MN-006 can use naphthalene as well as benzene.

\section{Monod growth kinetics}

Strains MN-003, MN-005 and MN-006 had maximal specific growth rates ( $\mu$-max) of $0.32 \pm 0.03$, $0.082 \pm 0.008$ and $0.30 \pm 0.02 \mathrm{~h}-1$, respectively, and half-saturation constants (Ks) of $2 \cdot 85 \pm 0 \cdot 54,0 \cdot 79 \pm 0 \cdot 10$ and $2 \cdot 52 \pm 0.32 \mathrm{mg} \mathrm{l}-1$, respectively, when grown with naphthalene as sole carbon source

\section{Discussion}

Screening for relatively fast-growing naphthalene-degrading bacteria from different sites which were contaminated with crude oil resulted in the recovery of three isolates B. naphthovorans strain MN003, Staphylococcus sp. strain MN-005 and Micrococcus sp. strain MN-006. Although the isolation methods select for both Gram-positive and Gram-negative bacteria, all three candidate strains were Gram-positive. This dominance of Gram-positive bacteria is demonstrated in the high relative abundances of B.naphthovorans strain MN-003, Staphylococcus sp. strain MN-005 and Micrococcus sp. strain MN-006 in the enrichment culture. The three strains constituted more than $63 \%$ of the total culturable heterotrophic bacteria and more than $69 \%$ of the culturable naphthalene-degrading bacteria in the enrichment culture. The dominance of Gram-positive bacteria should not be surprising. Gram-positive bacteria have a stronger cell envelope than Gram-negative bacteria and this allows them to thrive in the highly variable intertidal sediment environment, where sediment temperatures are high in the day and osmotic pressures and nutrient supply may change periodically over a daily cycle.

Many different species of bacteria with the ability to degrade naphthalene and other PAHs have been isolated, mostly from soil environments. The majority of the PAH-degrading bacteria were previously found to belong to the genus Pseudomonas, and the PAH-degradative gene clusters in these bacteria were highly homologous to the naphthalene gene (nah gene) cluster from the NAH7 plasmid in Pseudomonas putida strain G7 (Cerniglia1993). However, recent investigations of contaminated soils have uncovered naphthalenedegrading bacteria that did not hybridize with NAH7-derived gene probes (Ahn et al. 1999; LloydJones et al. 1999), and indicate that there are still many unidentified bacteria with diverse PAH biodegradation pathways that involve hitherto undiscovered genes and gene clusters. The microbial communities in environments have generally been reported to be dominated by Gram-negative bacteria. However, there is little information on Gram-positive naphthalene-degrading bacteria environment, although $\mathrm{PAH}$-degrading bacteria belonging to the Gram-positive family. These experiments suggest that Gram-positive bacteria may play a key role in PAH degradation. The relative abundance of strains in the naphthalene-fed enrichment culture experiment and in the batch culture competition studies was MN-003 > MN-006 > MN-005. This trend in relative abundance follows the trend in the maximal specific growth rates exhibited by the three strains when grown on naphthalene. Strain MN-003 had the fastest maximal specific growth rate, while the growth rates of strains MN-005 and MN-006 were slower than that of strain MN-003 by 74 and $6 \%$, respectively. Strain MN005 had a maximal specific growth rate that was significantly smaller than the other two strains. Although strain MN-005 had the smallest half-saturation constant of $0.79 \mathrm{mg} \mathrm{l}^{-1}$ and, consequently, the largest substrate affinity for naphthalene, it was outcompeted in all competition experiments by strains $\mathrm{MN}-003$ and MN-006, even at the lowest tested naphthalene concentration of $1 \mathrm{mg} \mathrm{l}^{-1}$. All the three strains, the dominant position of strain MN003 appears to be related to its superior ability to grow on naphthalene as there are no specific reasons why the bacilli would be expected to out compete cocci in culture. Endospores are highly resistant to environmental insults (e.g. heat, desiccation, radiation, oxidants and proteases) and allow the bacilli to persist and be ubiquitous in the environment without losing the capacity for germination and outgrowth (Francis and Tebo 2002). Strain MN-003 was successfully isolated using both the direct isolation method and the enrichment isolation method. Strains MN-005 and MN-006 were isolated by the enrichment isolation method and could not be obtained by direct isolation. The direct isolation method involves growing isolates directly from environmental samples and is often used to isolate the dominant members in a microbial community. The enrichment isolation method entails a period of acclimatization in the laboratory to produce an enrichment culture from which the microorganisms of interest are subsequently isolated. The isolates that are obtained from the enrichment isolation 
method may not necessarily to be dominant bacterial members in the original environmental sample. Strain MN003 is likely a dominant member of the microbial community in the oil-contaminated sediment and has potential for application in bioremediation schemes. This is based on its high maximal specific growth rate and its high relative abundance in enrichment culture and in the competition batch cultures. These results indicate the use of the direct isolation method to discover environmentally important strains.

\section{Conclusion}

Naphthalene is the simplest example of a PAH. PAHs occur in oil, coal, and tar deposits, and are produced as byproducts of fuel burning (whether fossil fuel or biomass). Common naphthalene degrading bacteria include Pseudomonas spp., Vibrio spp., Mycobacterium spp., Staphylococcus spp., and Sphingomonas spp. The relative abundance of strains in the naphthalene-fed enrichment culture experiment and in the batch culture competition studies was MN-003 > MN-006 > MN-005the growth rates of strains MN-005 and MN-006 were slower than that of strain MN-003 by 74 and 6\%, respectively. Strain MN-005 had a maximal specific growth rate that was significantly smaller than the other two strains. Although strain MN-005 had the smallest half-saturation constant of $0.79 \mathrm{mg} \mathrm{l}^{-1}$ and, consequently, the largest substrate affinity for naphthalene, it was outcompeted in all competition experiments by strains MN-003 and MN-006, even at the lowest tested naphthalene concentration of $1 \mathrm{mg} \mathrm{l}^{-1}$. All the three strains, the dominant position of strain MN-003 appears to be related to its superior ability to grow on naphthalene as there are no specific reasons why the bacilli would be expected to outcompete cocci in culture Strain MN-003 is likely a dominant member of the microbial community in the oil-contaminated sediment and has potential for application in bioremediation schemes. This is based on its high maximal specific growth rate and its high relative abundance in enrichment culture and in the competition batch cultures. These results indicate the use of the direct isolation method to discover environmentally important strains. More experimental work is still to do on such strains and characterization is needed

\section{References}

[1] Akhavan Sepahi. A., Dejban Golpasha. I., Nakhoda. A.M. Journal of Microbial World, 2009, 1(1), 5-14.

[2] Alquati, C., Papacchini, M., et al. Diversity of naphthalene degrading bacteria from a petroleum contaminated soil. Annals of Microbiology, 2005, 55 (4), 237-242.

[3] Bastiaens, L. et al. Isolation of adherent polycyclic aromatic hydrocarbon (PAH)-degrading bacteria using PAH-sorbing carriers. Appl. Environ. Microbiol, 2000, 66, 1834-1843.

[4] Bisht. S., Pandey. P., et al. Brazilian Journal of Microbiology, 2010, 41, 922-930.

[5] Canet, R., Birnstingl, J.G., Malcolm, D.G., LopezReal, J.M., Beck, A.J. Biodegradation of polycyclic aromatic hydrocarbons (PAHs) by native microflora and combination of white rot fungi in coal tar contaminated soil. Bioresource technology, 2001, 76 (2), 113117.

[6] Castorena- Torres, F., M. Bermudez de Leon, et.al. Changes in gene expression induced by polycyclic aromatic hydrocarbons in the human cell line HepG2 and A549. Toxicol. In vitro, 2008, 22, 411-421.

[7] Cebron, A.; Norini, M-P.; Beguiristain, T.; Leyval, C. Real-Time PCR quantification of PAH ring hydroxylating dioxygenase (PAH-RHD $\alpha$ ) genes from Gram positive and Gram negative bacteria in soil and sediment samples. J. Microbiol. Methods 2008, 73, $148-159$

[8] Dennis, J.J.; Zylstra, G.J. Complete sequence and genetic organization of pDTG1, the 83kilobase naphthalene degradation plasmid from Pseudomonas putida strain NCIB 9816-4. J. Mol. Biol. 2004, 341, 753-768.

[9] Ahn, Y., Sanseverino, J. and Sayler, G.S. (1999) Analyses of polycyclic aromatic hydrocarbon-degrading bacteria isolated from contaminated soils. Biodegradation 10, 149-157. CrossRef, PubMed,CAS, Web of Science®

[10] Berardesco, G., Dyhrman, S., Gallagher, E. and Shiaris, M.P. (1998) Spatial and temporal variation of phenanthrene-degrading bacteria in intertidal sediments. Applied and Environmental Microbiology 64, 2560-2565. PubMed, Web of Science ${ }^{\circledR}$

[11] Buck, J.D. (1982) Nonstaining (KOH) method for determination of Gram reactions of marine bacteria. Applied and Environmental Microbiology 44, 992-993. PubMed,CAS, Web of Science®

[12] Cerniglia, C.E. (1993) Biodegradation of polycyclic aromatic hydrocarbons. Current Opinion in Biotechnology 4, 331-338.Daane, L.L., Harjono, I., Zylstra, G.J. and Haggblom, M.M. (2001) Isolation and characterization of polycyclic aromatic hydrocarbondegrading bacteria associated with the rhizosphere of salt marsh plants. Applied and Environmental Microbiology 67, $2683-2691$. CrossRef, PubMed Web of Science ${ }^{\circledR}$

[13] Dyksterhouse, S.E., Gray, J.P., Herwig, R.P., Lara, J.C. and Staley, J.T. (1995) Cycloclasticus pugetii gen. nov., sp. nov., and aromatic hydrocarbon-degrading bacterium from marine sediments. International Journal of Systematic Bacteriology 45, 116123.CrossRef, PubMed,Web of Science ${ }^{\circledR}$ 